\title{
RED CELL DISTRIBUTION WIDTH AS A MARKER OF PREECLAMPSIA SEVERITY
}

\author{
Shilpa Gopal Reddy¹, Harendra Kumar², Geetanjali Nagaraj33, Pushpa P. Kottur ${ }^{4}$ \\ ${ }^{1}$ Assistant Professor, Department of Pathology, Sri Devraj Urs Medical College. \\ ${ }^{2}$ Professor, Department of Pathology, Sri Devraj Urs Medical College. \\ ${ }^{3}$ Post Graduate Student, Department of Pathology, Sri Devraj Urs Medical College. \\ ${ }^{4}$ Professor, Department of Obstetrics and Gynaecology, Sri Devraj Urs Medical College.
}

\section{ABSTRACT}

\section{BACKGROUND}

Red cell distribution width, used traditionally to differentiate various types of anaemia is also documented to be associated with severity of hypertension in non-pregnant population. However, there is scarcity of its usefulness in hypertensive disorders of pregnancy. This study was undertaken to examine the role of red cell distribution width in predicting the severity of preeclampsia.

\section{MATERIAL AND METHODS}

One hundred and forty three patients of preeclampsia and nine hundred and eleven normal pregnancy cases were included in the study during a period of one year. The severity of preeclampsia was classified as mild $(n=76)$ or severe $(n=67)$.

\section{RESULTS}

Red cell distribution width was significantly higher in severe preeclampsia group $(p<0.001)$. It was positively correlating with mean arterial pressure with $\mathrm{r}=0.343 ; \mathrm{p}<0.001$. Receiver operating characteristic curve analysis showed area under curve of 0.766 , $95 \%$ Confidence Interval (CI) $0.70-0.83$. Cut off value of $>15.9 \%$ was found to have significant value for differentiating mild and severe forms of preeclampsia.

\section{CONCLUSION}

Red cell distribution width is associated with preeclampsia and has a good diagnostic significance in severe preeclampsia.

\section{KEYWORDS}

Preeclampsia, Red Cell Distribution Width, Hypertension.

HOW TO CITE THIS ARTICLE: Reddy SG, Kumar H, Nagaraj G, et al. Red cell distribution width as a marker of preeclampsia severity. J. Evolution Med. Dent. Sci. 2016;5(48):3104-3107, DOI: 10.14260/jemds/2016/720

\section{INTRODUCTION}

Preeclampsia is a multi-organ disease characterized by the development of hypertension. The World Health Organization estimates that preeclampsia is directly responsible for $10 \%$ of direct maternal mortality in Asia and also leads to significant neonatal morbidity and mortality.[1] Major pathophysiological process in the development of this disorder include incomplete invasion of the trophoblasts into spiral arterioles leading to endothelial dysfunction and activation. ${ }^{[2]}$ Increased erythropoietic stimulation due to placental hypoxia has also been described in the literature.[3]

Red Cell Distribution Width (RDW) estimates the degree of heterogeneity of the erythrocyte volume. It is evaluated in a fully automated haematology analyser as a part of Complete Blood Count (CBC) and has a high sensitivity in the differential diagnosis of anaemia. However, recent evidence has shown that increased levels are also seen in hypertension and other cardiovascular disorders. ${ }^{[4,5]}$ It is also associated with diabetic ketoacidosis, thrombotic disorders, malignancies and hepatorenal diseases.[6,7,8] However, there is limited data on the usefulness of RDW in pregnant population and especially the hypertensive disorders of pregnancy.[9]

Financial or Other, Competing Interest: None.

Submission 14-05-2016, Peer Review 25-05-2016,

Acceptance 28-05-2016, Published 16-06-2016.

Corresponding Author:

Dr. Shilpa Gopal Reddy,

\#28, Chandavi, $12^{\text {th }}$ Main,

1 st Stage, BTM Layout,

Bangalore- 560029.

E-mail: gshilp@gmail.com

DOI: $10.14260 /$ jemds $/ 2016 / 720$
Therefore, the current study was undertaken to study the relationship between RDW and preeclampsia in Indian population and to investigate if it can be used as a severity marker.

\section{MATERIALS AND METHODS}

This study was conducted in the Department of Pathology in collaboration with Department of Obstetrics and Gynaecology, RL Jalappa Hospital and Research Centre attached to Sri Devraj Urs Medical College, Kolar; 67 cases of severe preeclampsia, 76 cases of mild preeclampsia and 911 cases of normal pregnancies admitted during the study periods of one year between January to December 2015 were included. Preeclampsia was diagnosed according to the criteria of American College of Obstetrics and Gynaecology.[10] The case was classified as mild when a systolic blood pressure of 140 $\mathrm{mmHg}$ or higher/a diastolic blood pressure of $90 \mathrm{mmHg}$ or higher was occurring after 20 weeks of gestation in a woman whose blood pressure was previously normal.

Severe preeclampsia was defined if the pregnant woman had any one of the following criteria - systolic blood pressure of $160 \mathrm{mmHg}$ or more/diastolic blood pressure of $110 \mathrm{mmHg}$ or more on two occasions, six or more hours apart; oliguria with excretion of less than $500 \mathrm{~mL}$ urine in 24 hrs.; pulmonary oedema or cyanosis; impairment of liver function tests; visual or cerebral disturbances; pain in epigastric area or right upper quadrant; decreased platelet count. Pregnant women with evidence of haemolysis, iron, vitamin B12 or folate deficiencies, diabetes mellitus, chronic hypertension, premature rupture of membranes, in active labour, polyhydramnios, anaemia, kidney disorders who received 
transfusions and those with signs of concurrent medical complications including infectious diseases were excluded from the study.

After obtaining informed written consent $3 \mathrm{~mL}$ of venous blood was obtained from each patient in the third trimester, but before the onset of labour and collected into vacutainers containing Ethylenediaminetetraacetic Acid (EDTA). The CBC was analysed using Beckman Coulter Act 5 Diff cell counter and recorded. The age, gestational age, body mass index, blood pressure measurement and pregnancy outcome were recorded for each case.

\section{Statistical Analysis}

Data analysis was performed using the Statistical Package for Social Sciences for Windows, version 16.0 (SPSS Inc., Chicago, IL, USA). Significance was set at $\mathrm{p}<0.05$. The sample size included in this study yields more than $80 \%$ power to detect a 0.5 Standard Deviation (SD) difference in levels of RDW between groups with a significance level of $\alpha=0.05$. Continuous data were expressed as mean $\pm \mathrm{SD}$, while categorical data were presented as number of patients. A OneWay Analysis of Variance (ANOVA) was used to compare the characteristics between healthy pregnant women and pregnant women with preeclampsia. Statistical significance was determined using multiple comparisons between the groups performed by a One-Way ANOVA. The participants' CBCs were analysed by the same statistical method. The strength of the association between RDW and Mean Arterial Pressure (MAP) was estimated using the Pearson correlation coefficient (r). To estimate the sensitivity value of RDW as a severity marker of preeclampsia, Receiver Operating Characteristic (ROC) analysis was performed.

\section{RESULTS}

The demographic and clinical characteristics of the participants are shown in Table 1. Compared to normal pregnancy cases the participants in study group were more often nulliparous, had higher Body Mass Index (BMI) and gave birth to neonates with lower birth weight. However, there was no significant difference in maternal and gestational age between the groups. As expected women with severe and mild preeclampsia had elevated Mean Arterial Pressure (MAP).

Among the complete blood count parameters evaluated (Table 2), the haemoglobin level was not statistically significant between groups. White blood cell count was higher in preeclamptic group, while platelet counts were lowest in the severe preeclampsia group $(\mathrm{p}<0.001)$. Red cell distribution width was significantly increased in severe pre-eclampsia group above the normal range of $11-14 \%$. It was significantly increased when compared with normal pregnancy and mild preeclamptic group $(\mathrm{p}<0.001)$. RDW was positively correlated with MAP, which is the best known severity marker of preeclampsia with $r=0.343$; $p<0.001$ (Figure 1).

Area under curve for RDW in ROC curve analysis showed that it had good diagnostic significance with AUC $=0.766,95 \%$ Confidence Interval (CI) 0.70-0.83. (Figure 2) Next in order to estimate the cut-off value of the parameter to differentiate severe form of preeclampsia from mild preeclampsia, we investigated the sensitivity and specificity. RDW at a cut-off value of $>15.9 \%$ had a sensitivity of $71.3 \%$ and specificity of $65 \%$.

\begin{tabular}{|c|c|c|c|c|}
\hline Parameters & $\begin{array}{c}\text { Severe Pre- } \\
\text { Eclampsia } \\
\text { (n=67) }\end{array}$ & $\begin{array}{c}\text { Mild Pre- } \\
\text { Eclampsia } \\
\text { (n=76) }\end{array}$ & $\begin{array}{c}\text { Normal } \\
\text { Pregnancy } \\
\text { (n=911) }\end{array}$ & $\begin{array}{c}\text { P } \\
\text { value }\end{array}$ \\
\hline Age (Years) & $23.7 \pm 3.3$ & $23.1 \pm 3.2$ & $23.3 \pm 3.7$ & 0.522 \\
\hline Body Mass Index (kg/m²) & $30.21 \pm 7.25$ & $28.2 \pm 6$ & $26.25 \pm 5.15$ & $<0.0001$ \\
\hline Gestation age (Weeks) & $36.5 \pm 2$ & $36.9 \pm 1$ & $38 \pm 2.5$ & 0.108 \\
\hline Nulliparous (\%) & 42 & 42 & 0.00003 & - \\
\hline Mean arterial pressure (mmHg) & $125.1 \pm 8.7$ & $112.1 \pm 4$ & $25.4 \pm 5.1$ & $<0.001$ \\
\hline Birth weight of the neonates (kg) & $2.6 \pm 0.6$ & $2.7 \pm 0.4$ & $2.8 \pm 0.5$ & 0.004 \\
\hline \multicolumn{2}{|r|}{ Table 1: Demographic and Clinical Characteristics of the Study Groups } \\
\hline
\end{tabular}

\begin{tabular}{|c|c|c|c|c|}
\hline Parameters & $\begin{array}{l}\text { Severe Pre- } \\
\text { Eclampsia } \\
(n=67)\end{array}$ & $\begin{array}{l}\text { Mild Pre- } \\
\text { Eclampsia } \\
(n=76)\end{array}$ & $\begin{array}{c}\text { Normal } \\
\text { Pregnancy } \\
(n=911)\end{array}$ & $\begin{array}{c}P \\
\text { value }\end{array}$ \\
\hline $\begin{array}{c}\text { WBC }\left(x 10^{3} \mu \mathrm{L}\right) \\
\text { Post hoc }\end{array}$ & $10.4 \pm 2$ & $10 \pm 3.4$ & $7.8 \pm 1.9$ & $<0.001$ \\
\hline Haemoglobin (mg/dL) & $12.5 \pm 1.6$ & $12.3 \pm 0.9$ & $12.6 \pm 1.3$ & 0.1287 \\
\hline Platelet $\left(\mathrm{x} 10^{3} \mu \mathrm{L}\right)$ & $132 \pm 62.02$ & $198.63 \pm 36.63$ & $351.17 \pm 77.4$ & $<0.001$ \\
\hline RDW (\%) & $18.01 \pm 3.4$ & $14.8 \pm 3.1$ & $12.8 \pm 2.1$ & $<0.001$ \\
\hline
\end{tabular}




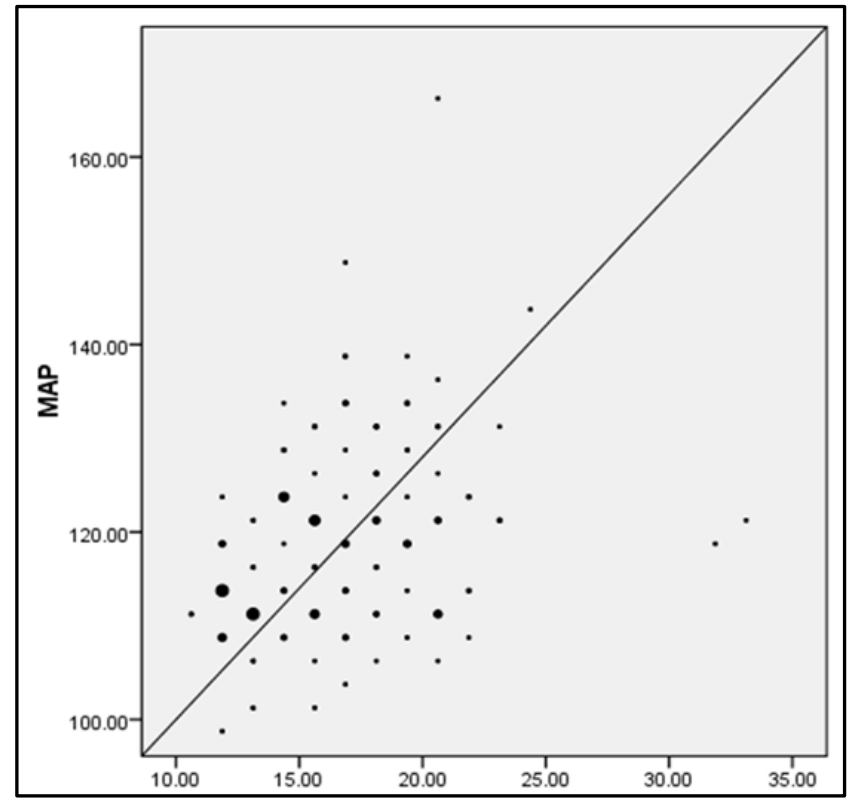

Fig. 1: Correlation between RDW and MAP

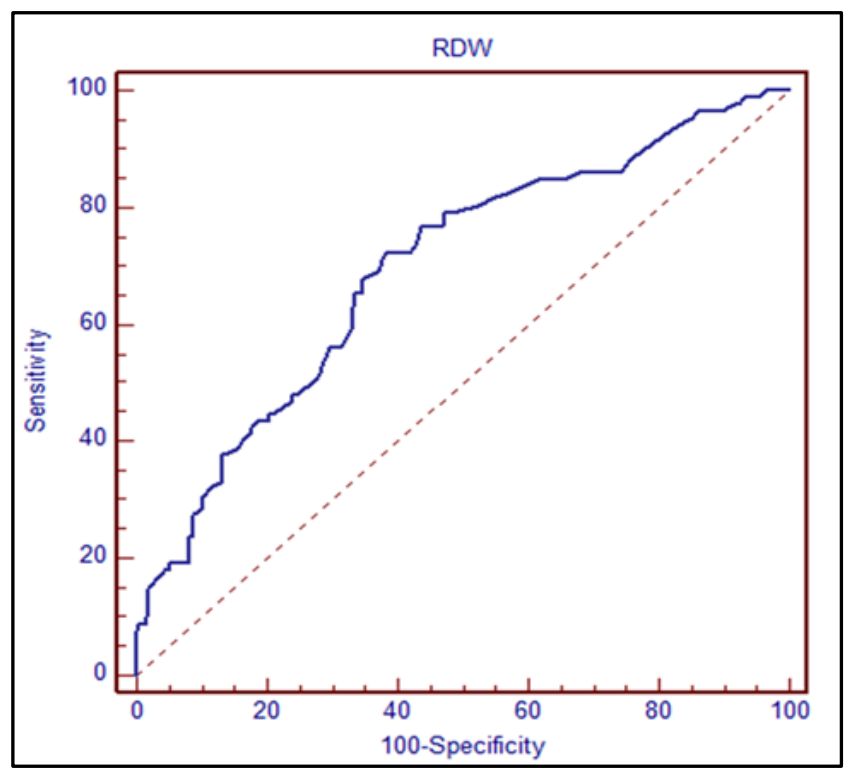

Fig. 2: The Receiver Operating Characteristic (ROC) Curve of RDW in the Preeclampsia Group to Identify the Optimal Cut-Off Level for the Prediction of Severity of Preeclampsia

\section{DISCUSSION}

The results from our study showed that there is a relationship between RDW and preeclampsia with significantly higher levels seen in severe preeclampsia cases. We have also demonstrated that RDW can be used to differentiate between mild and severe forms of preeclampsia.

RDW, a marker of erythrocyte anisocytosis, is traditionally used for differential diagnosis of anaemia. However, recent studies have found that it is correlated strongly with heightened systolic and diastolic blood pressure and is a poor prognostic indicator in cardiovascular disorders. ${ }^{[4,5,11]}$ Ozcan et al have attributed the rise of RDW in hypertensive disorders to the increased inflammatory response.[12] By impairment of iron metabolism and disturbance in erythropoiesis, it could also result in the release of excess of reticulocytes and disruption in erythrocyte maturation.[13]
Preeclampsia is a syndrome characterized by the new onset of hypertension affecting both mother and foetus. The association between RDW and preeclampsia can be explained by several theories. In preeclampsia, there is incomplete invasion of trophoblasts into spiral arterioles leading to endothelial dysfunction and activation. This leads to excessive maternal vascular inflammatory response. [14] Preeclampsia is associated with rise in tumour necrosis factor $\alpha$ and interleukin 6 levels.[15] The increased inflammation results in destruction of RBCs and disturbance in erythropoietin release. Hence, there is release of young RBCs and reticulocytes into the circulation causing anisocytosis in preeclampsia. Reticulocytosis in peripheral blood can also be attributed to the deposition of fibrinoid material and foam cells around the arteriole in preeclampsia.[16] Hence, there is placental hypoxia and increased erythropoietic activity, which was also demonstrated by Troeger et al in their study involving preeclamptic patients.[3] This results in stimulation of bone marrow leading to increased release of immature RBCs. However, the resulting anisocytosis measured by RDW, is due to the disease itself or a reflection of an underlying cause or both elements is still unclear.

Our study is in concordance with findings of study done by Kurt et al involving 35 patients with mild preeclampsia and 17 patients of severe preeclampsia. They have also shown that severe preeclamptic cases had higher RDW values. They also demonstrated a positive correlation between RDW and Creactive protein.[9] In addition our study shows that RDW can also be used to differentiate the severe form of preeclampsia from the mild form. However, a study done by Abdullahi et al involving 65 patients of preeclampsia in Sudanese population did not show correlation between RDW and preeclampsia.[17] The probable cause could be due to a high prevalence of anaemia in their study population, which could have resulted in high RDW.[18]

\section{CONCLUSION}

Due to its varied clinical presentation, proper diagnosis of preeclampsia is still an issue, especially in community health centres. There is a need for an affordable test that could offer a pre-symptomatic diagnosis of preeclampsia. RDW is a simple, inexpensive and routinely used parameter available to health care givers as a part of CBC. In the present study, we have demonstrated that RDW is associated with the presence and severity of preeclampsia and can be used to identify the severe preeclampsia. Further studies involving larger population are required to evaluate the usefulness of RDW as a candidate marker for predicting the occurrence of severe preeclampsia.

\section{REFERENCES}

1. Cripe S, Obrien W, Gelaye B, et al. Perinatal outcomes of Southeast Asians with pregnancies complicated by gestational diabetes mellitus or preeclampsia. Journal of Immigrant and Minority Health 2012;14(5):747-53.

2. Powe CE, Levine RJ, Karumanchi SA. Preeclampsia, a disease of the maternal endothelium: the role of antiangiogenic factors and implications for later cardiovascular disease. Circulation 2011;123(24):285669. 
3. Troeger C, Holzgreve W, Ladewig A, et al. Examination of maternal plasma erythropoietin and activin A concentrations with regard to circulatory erythroblast levels in normal and preeclamptic pregnancies. Fetal Diagn Ther 2006;21(1):156-60.

4. Tanindi A, Topal FE, Topal F, et al. Red cell distribution width in patients with prehypertension and hypertension. Blood Press 2012;21(3):177-81.

5. Isik T, Kurt M, Ayhan E, et al. The impact of admission red cell distribution width on the development of poor myocardial perfusion after primary percutaneous intervention. Atherosclerosis 2012;224(1):143-9.

6. Montagnana M, Cervellin G, Meschi T, et al. The role of red blood cell distribution width in cardiovascular and thrombotic disorders. Clin Chem Lab Med 2011;50(4):635-41.

7. Liu DS, Jin Y, Ma SG, et al. The ratio of red cell distribution width to mean corpuscular volume in patients with diabetic ketoacidosis. Clin Lab 2013;59(9-10):1099104.

8. Salvagno GL, Sanchis-Gomar F, Picanza A, et al. Red blood cell distribution width: a simple parameter with multiple clinical applications. Critical reviews in clinical laboratory sciences 2015;52(2):86-105.

9. Kurt RK, Aras Z, Silfeler DB, et al. Relationship of red cell distribution width with the presence and severity of preeclampsia. Clin Appl Throm Hemost 2013, DOI: 10.1177/1076029613490827.

10. Hypertension in pregnancy. Report of the American College of Obstetricians and Gynaecologists' Task Force on Hypertension in Pregnancy. Obstet Gynaecol 2013;122(5):1122-31.
11. Patel KV, Ferrucci L, Ershler WB, et al. Red blood cell distribution width and the risk of death in middle-aged and older adults. Arch Intern Med 2009;169(5):515-23.

12. Ozcan F, Turak O, Durak A, et al. Red cell distribution width and inflammation in patients with non-dipper hypertension. Blood Press 2013;22(2):80-5.

13. Brovelli A, Castellana MA, Minetti G, et al. Conformational changes and oxidation of membrane proteins in senescent human erythrocytes. Adv Exp Med Biol 1991;307:59-73.

14. Goel A, Rana S. Angiogenic factors in preeclampsia: potential for diagnosis and treatment. Current opinion in nephrology and hypertension 2013;22(6):643-50.

15. Kronborg CS, Gjedsted J, Vittinghus E, et al. Longitudinal measurement of cytokines in preeclamptic and normotensive pregnancies. Acta Obstet Gynaecol Scand 2011;90(7):791-6.

16. Belo L, Rebelo I, Castro EM, et al. Band 3 as a marker of erythrocyte changes in pregnancy. European Journal of Haematology 2002;69(3):145-51.

17. Abdullahi H, Osman A, Rayis DA, et al. Red blood cell distribution width is not correlated with preeclampsia among pregnant Sudanese women. Diagn Pathol 2014;9:29.

18. Abdelrahim II, Mahgoub HM, Mohamed AA, et al. Anaemia, folate, zinc and copper deficiencies among adolescent schoolgirls in Eastern Sudan. Biol Trace Elem Res 2009;132(1-3):60-6. 